\title{
Rescuing Christensenia aesculifolia (Marattiaceae), a plant species with an extremely small population in China
}

\author{
Lei Cai, Guiliang Zhang, Jianying Xiang, Zhiling Dao and Weibang Sun
}

\begin{abstract}
The rare and threatened fern Christensenia aesculifolia of South-east Asia is listed in China as a secondranked plant for national protection and is also categorized as one of 62 plant species with extremely small populations by the Yunnan provincial government. Field investigations during 2014-2017 failed to relocate one previously known population, and revealed that the single known extant population of C. aesculifolia contains only 10 individual plants. The most urgent conservation requirement for this species is to conserve the threatened habitat of the remnant population. Further field surveys and research are also required for an improved understanding of the species' status.
\end{abstract}

Keywords China, Christensenia aesculifolia, conservation, Marattiaceae, plant species with extremely small populations, population status, rescue

n China there is a particular focus on the conservation of
plant species categorized as having extremely small
populations. One of these is the fern Christensenia aesculifolia
(Bl.) Maxon (Marattiaceae) (with the synonyms Aspidium aes-
culifolium, Christensenia assamica, Christensenia lobbiana,
Kaulfussia aesculifolia, Kaulfussia assamica, Kaulfussia
korthalsii and Kaulfussia lobbiana), which is found through-
out limestone areas of South-east Asia (Rolleri, 1993; He \&
Christenhusz, 2013). Although this species is widely distribu-
ted, the number of populations is low. Christensenia aesculi-
folia has not yet been assessed for the IUCN Red List but it
was listed as a provincial second-ranked protected wild plant
in Yunnan in 1989, and as a national second-ranked protected
wild plant in China in 1999. In March 2010 it was identified as
one of 62 plant species with extremely small populations in
Yunnan because of its small remaining population, restricted
habitat, a high degree of disturbance from people, and a high
risk of extinction (Ma et al., 2013; Sun, 2013; Wang et al., 2016;

Lei Cai ${ }^{*}$, Zhiling Dao and Weibang Sun (Corresponding author) Kunming Botanical Garden, Kunming Institute of Botany, Chinese Academy of Sciences; Yunnan Key Laboratory for Integrative Conservation of Plant Species with Extremely Small Populations, Kunming, Yunnan 650201, China E-mail wbsun@mail.kib.ac.cn

Guiliang Zhang Hekou Forestry Bureau, Yunnan, China

Jianying Xiang Yunnan Academy of Biodiversity, Kunming, Yunnan, China

${ }^{*}$ Also at: University of Chinese Academy of Sciences, Beijing, China

Received 6 August 2017. Revision requested 18 February 2018.

Accepted 26 February 2018. First published online 15 August 2018.
Diniz et al., 2017). In 2013 C. aesculifolia was categorized nationally as Critically Endangered on the China Biodiversity Red List (on the basis of criteria Blab(i,ii) $+2 \mathrm{a}(\mathrm{i}, \mathrm{ii}), \mathrm{C} 2 \mathrm{a}(\mathrm{i})$ ), and in 2017 it was included in the Threatened Species List of China's Higher Plants because of the extremely low numbers of individuals in China (Qin et al., 2017).

Christensenia aesculifolia has the largest synangia on the back of the leaves of any fern; this is one of its distinguishing features. It does not resemble a typical fern, and without sporangia appears similar to Typhonium trilobatum (L.) Schott and is often mistaken for a species of Araceae.

Surveys in October 2014 (for 8 days by six people), August 2015 (3 days by five people), September 2016 ( 5 days by four people) and April and November 2017 ( 6 days by four people) led by LC in Lvchun, Jinping and Hekou Counties, Honghe Prefecture, and in November 2015 ( 5 days by six people) and August 2017 (6 days by seven people) led by ZD in Malipo and Maguan Counties, Wenshan Prefecture, found only one locality, with 10 individual plants, in an area of c. $500 \mathrm{~m}^{2}$ in a karst rainforest in Hekou County (Fig. 1). Christensenia aesculifolia was formerly also known from Jinping County but this population seems to have disappeared as a result of the destruction of its habitat; it was last recorded there in the 1980s.

In general deforestation is the main cause of the destruction of natural vegetation in Yunnan, with trees felled to support social and economic development and for the planting of banana and rubber trees. The area in which the extant population of $C$. aesculifolia occurs in Hekou is being used by farmers for planting Amomum villosum Lour. However, the population is in a valley, at the edge of an $A$. villosum field, and thus has not been completely removed by farmers (Plate 1), who clean away weeds (including C. aesculifolia) around the A. villosum field. In a similar manner, habitat loss and fragmentation are the main threats to other plant species in China that have extremely small populations (Ren et al., 2012, 2014; Chen et al., 2014; Li et al., 2014; Volis, 2016).

Although the remnant population of C. aesculifolia is within Daweishan National Nature Reserve, the effectiveness of protection is low and a small dedicated protected area is required to protect the few remaining individuals and their habitat, with logging and setting of fires prohibited. We have worked with the local government and farmers, who have now halted farming activities in this area, and we are also carrying out regular patrols to protect the remaining plants. 


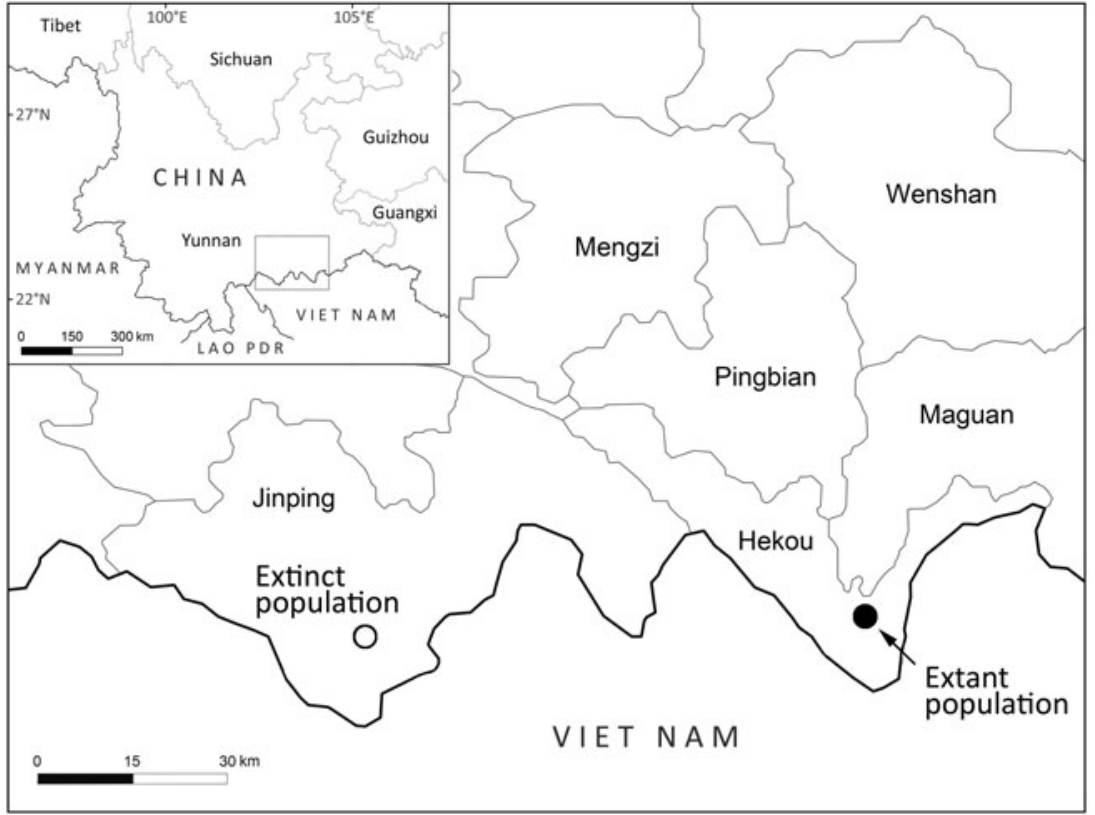

FIG. 1 Location of the extant population in Hekou County and of the lost population in Jingping County.
Additionally, we plan to erect appropriate advisory signs and a plaque explaining conservation goals for C. aesculifolia, construct fencing, and hire specialized staff.

In October 2014 and November 2016 we collected spores of $C$. aesculifolia for preliminary germination experiments, but these failed, perhaps because the spores were collected from plants already cut down by farmers. In November 2017 we collected mature spores and several young shoots from living wild plants for breeding and cultivation at Kunming Botanical Garden; germination trials are ongoing. As of November 2017 the rhizomes of the 10 plants located in the wild are all growing.
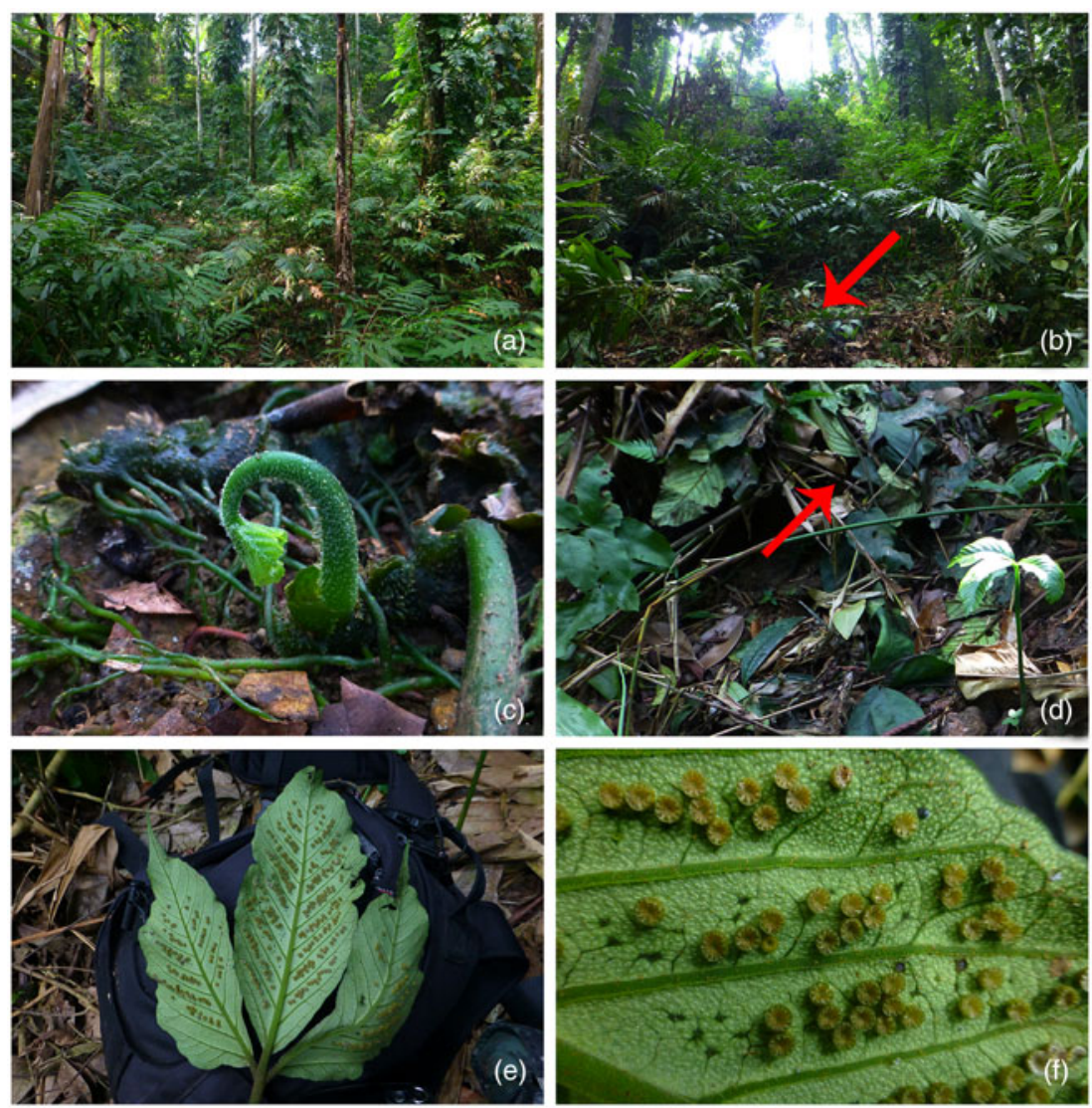

Plate 1 Christensenia aesculifolia, showing (a) its natural habitat, (b) habitat destruction, (c) bud, (d) destruction of individual plants, and (e) and (f) plants cut down by farmers, showing spores. 
An ex situ collection of C. aesculifolia at Kunming Botanical Garden was introduced from Hekou County in 2014, but is not thriving. There are two other small populations in cultivation in China, both of which were originally obtained from the population at Hekou County: a small population in Xishuangbanna Tropical Botanical Garden and two plants in Shenzhen Fairylake Botanical Garden.

Public education, especially of local residents, is a crucial element of any conservation strategy for plant species with extremely small populations. We have developed mechanisms for providing public education about the importance of protecting plant species with extremely small populations, both at Kunming Botanical Garden and among local communities in the native range of several other such species: Bretschneidera sinensis, Coptis quinquesecta, Cycas spp., Magnolia spp., Paphiopedilum spp. and Paraisometrum mileense.

As with other plant species with extremely small populations, C. aesculifolia is rare in China and the population is in urgent need of rescue. Despite the advances described here, further field surveys and research are required for an improved understanding of the species' status. Protection against human disturbance and in situ conservation are currently the most urgent tasks.

Acknowledgements This work was supported by the Science \& Technology Basic Resources Investigation Program of China (2017FY100100), Yunnan Provincial Wildlife Conservation Projects (201606).

Author contributions Writing: LC; revision and editing: JX, WS; fieldwork: GZ, ZD, LC.

\section{Conflicts of interest None.}

Ethical standards This research complied with the Oryx Code of Conduct.

\section{References}

Chen, Y.K., YanG, X.B., YAnG, Q., LI, D.H., Long, W.X. \& Luo, W.Q. (2014) Factors affecting the distribution pattern of wild plants with extremely small populations in Hainan Island, China. PLoS ONE, 9, e97751.

Diniz, M.F., Goncalves, T.V. \& Brito, D. (2017) Last of the green: identifying priority sites to prevent plant extinctions in Brazil. Oryx, 51, 131-136.

He, Z.R. \& Christenhusz, M.J.M. (2013) Marattiaceae. In Flora of China, Vol. 2 (eds Z.Y. Wu \& P.H. Raven), pp. 82-89. Science Press, Beijing, China, \& Missouri Botanical Garden Press, St. Louis, USA.

LI, B., ZHANG, Z.Y. \& ZHANG, D.X. (2014) Conservation status of the unique population of Wenchengia alternifolia, an enigmatic plant endemic to Hainan Island, China. Oryx, 48, 354-357.

Ma, Y.P., Chen, G., Grumbine, R.E., Dao, Z.L., Sun, W.B. \& Guo, H.J. (2013) Conserving plant species with extremely small populations (PSESP) in China. Biodiversity and Conservation, 22, 803-809.

Qin, H.N., YanG, Y., Dong, S.Y., He, Q., JiA, Y., ZhaO, L.N. et al. (2017) Threatened species list of China's higher plants. Biodiversity Science, 25, 696-744.

Ren, H., Jian, S., Chen, Y., Liu, H., Zhang, Q., Liu, N. et al. (2014) Distribution, status, and conservation of Camellia changii Ye (Theaceae), a Critically Endangered plant endemic to southern China. Oryx, 48, 358-360.

Ren, H., ZhanG, Q.M., Lu, H.F., LiU, X.H., Guo, Q.F., WANG, J. et al. (2012) Wild plant species with extremely small populations require conservation and reintroduction in China. Ambio, 41, 913-917.

Rolleri, C. (1993) Revision of the genus Christensenia. American Fern Journal, 83, 3-19.

Sun, W.B. (2013) Conserving Plant Species with Extremely Small Populations (PSESP) in Yunnan: Practice \& Exploration. Yunnan Science and Technology Press, Kunming, China. [In Chinese].

Volis, S. (2016) How to conserve threatened Chinese plant species with extremely small populations? Plant Diversity, 38, 45-52.

WAnG, B., MA, Y.P., Chen, G., LI, C.R., DAo, Z.L. \& Sun, W.B. (2016) Rescuing Magnolia sinica (Magnoliaceae), a Critically Endangered species endemic to Yunnan, China. Oryx, 50, 446-449. 